OPEN ACCESS

Edited by:

Corrado Romano,

Oasi Research Institute (IRCCS), Italy

Reviewed by:

Jolanta Pauk

Bialystok University of Technology, Poland

Paul Chase,

Ohio University, United States

*Correspondence:

Clare C. W. Yu

clare-chung-wah.yu@polyu.edu.hk

Specialty section:

This article was submitted to

Children and Health,

a section of the journal

Frontiers in Pediatrics

Received: 27 August 2020 Accepted: 07 December 2020

Published: 14 January 2021

Citation:

Wong SWL, Yu CCW and Li AM (2021) The Understanding of Peak Oxygen Uptake in Children Aged 8-16. Front. Pediatr. 8:599571. doi: 10.3389/fped.2020.599571

\section{The Understanding of Peak Oxygen Uptake in Children Aged 8-16}

\author{
Simpson W. L. Wong ${ }^{1}$, Clare C. W. Yu ${ }^{2 *}$ and Albert M. $L i^{3}$ \\ ${ }^{1}$ Department of Education Studies, Hong Kong Baptist University, Hong Kong, China, ${ }^{2}$ Department of Rehabilitation \\ Sciences, The Hong Kong Polytechnic University, Hong Kong, China, ${ }^{3}$ Department of Paediatrics, The Chinese University of \\ Hong Kong, Hong Kong, Hong Kong, China
}

Objective: To examine the understanding of the concept peak oxygen uptake (peak $\left.\mathrm{VO}_{2}\right)$ among children and adolescents at different ages from a developmental perspective.

Methods: A total of 549 children and adolescents aged 8 to 16 were recruited and instructed to fill in a 20-item Peak $\mathrm{VO}_{2}$ Understanding Inventory developed with reference to the research literature on peak $\mathrm{VO}_{2}$. We presented the participants with twenty scenarios and asked them to indicate whether peak $\mathrm{VO}_{2}$ would "remain unchanged," "increase," or "decrease," or that there was "insufficient information for a definite answer." The cross-sectional data was analyzed by employing a series of ANOVA analyses and chi-square association tests. Additional statistical analyses were performed to examine the error patterns and if there were gender differences.

Results: Except for the 8-year-old group, the overall accuracy rate did not improve with age. Age-related differences in the choice of answers ("increase," "decrease," "unchanged," and "uncertain") for determining the resulting peak $\mathrm{VO}_{2}$ after a change of antecedent were observed. Error analysis by item showed that prefactual thinking that is important to understand the concept was emerging rather than fully developed in our child and adolescent samples.

Conclusion: The mastery of peak $\mathrm{VO}_{2}$ is not subject to age-related maturation but might demand the acquisition of specific logical reasoning skill such as perfactual thinking. Early introduction of peak $\mathrm{VO}_{2}$ and related concepts is advocated and should be emphasized on the reasoning rather than providing model answers in physical literacy education.

Keywords: cognitive development, conservation, perfactual thinking, cardiovascular fitness, peak oxygen uptake, physical literacy

\section{INTRODUCTION}

Cardiopulmonary fitness is one of the most essential dimensions of health-related fitness, partly because of its close association with cardiovascular risk factors such as abdominal adiposity in children and adolescents $(1,2)$. According to several international standards, regular daily moderate-to-vigorous physical activity (MVPA) is recommended to ensure cardiopulmonary fitness. In spite of the well-known recommendations and the benefits of MVPA, many people still lead a sedentary lifestyle. One attempt to understand people's attitude toward physical activity is through a comprehensive examination of their physical literacy (3). To date, physical literacy is regarded as a multi-dimensional construct, encapsulating a series of parameters that explain an individual's participation in physical activities for life (4). Given the multi-faceted nature of physical 
literacy, a collection of assessment tools rather than a single measure are used for the evaluation of physical literacy. Among these tools, self-reported inventories are the most commonly used method. It has been shown in an empirical study that there was a significant correlation between the perceived and actual physical literacy (5). However, even if a person confidently reports that he/she is aware of the importance of the health concept (e.g., peak $\mathrm{VO}_{2}$ ) and believes they have enough knowledge about the concept, it is uncertain if this individual's belief is true. A direct measure of their health literacy can clarify this self-perception bias.

Among various indicators of cardiopulmonary fitness, the highest oxygen uptake elicited in a maximal exercise test to exhaustion is widely considered as the benchmark for such fitness assessment (6). This parameter is commonly referred to either as maximal oxygen uptake $\left(\mathrm{VO}_{2} \max \right)$ or as peak oxygen uptake (peak $\mathrm{VO}_{2}$ ); herein, the term "peak $\mathrm{VO}_{2}$ " is used. Despite the significance of peak $\mathrm{VO}_{2}$, little is known about whether this concept can be fully understood by children and adolescents. To the best of our knowledge, children and adolescents' understanding of peak $\mathrm{VO}_{2}$ has not been tested in any research study. Without this knowledge, it is not easy to plan the physical literacy curriculum designed for students at different years of age. The current study aims to fill these research and pedagogical gaps in health literacy.

By definition, peak $\mathrm{VO}_{2}$ is an abstract concept and thus cannot be observed with the naked eye. However, it is measurable through a maximal graded exercise test. In children, who are not health professionals and have only a limited basic knowledge of the human body, understanding the concept of peak $\mathrm{VO}_{2}$ requires several mental skills. The definition of peak $\mathrm{VO}_{2}$ includes a linguistic marker "superlative" ("highest" and "maximal") which may be difficult to comprehend for young children. Some notion of "oxygen," as the element that we breathe in to sustain our lives, is requisite. The ability to imagine the flow of oxygen through the cardiopulmonary system is also required to understand peak $\mathrm{VO}_{2}$. As a health concept, people's knowledge of the link between peak $\mathrm{VO}_{2}$ and its determinants is essential. Therefore, we examined peak $\mathrm{VO}_{2}$ by relating this concept to "if-then" conditional propositions structuring a causal relationship; that is, "if (cause, i.e., determinant), then (effect, i.e., the resulting peak $\mathrm{VO}_{2}$ )." Using "if-then" conditional propositions, we generated a series of hypothetical situations for testing children and adolescents' understanding of peak $\mathrm{VO}_{2}$.

Another main reason for formulating questions as "ifthen" conditional propositions was that such propositions guide goal-directed behaviors. The logic behind processing such propositions is prefactual thinking, (i.e., thinking how things might be different in the future). Thoughts assume the form of "if-then" conditional propositions in which "if" specifies an alternative action or condition (e.g., "if I do more exercise") and "then" specifies the imagined outcome or goal (e.g., "then my peak $\mathrm{VO}_{2}$ will increase"). Accordingly, such thinking enables consideration of different courses of action that may have led, or may still lead, to a more desirable outcome, preparing one to implement such actions through a range of futureoriented cognitions if a comparable situation arises in the future.
Furthermore, prefactual thoughts are essential because they focus on controllable elements (e.g., concentration level or specific strategies to improve skills). By imagining how things might be different in the future, people become more aware that the constraints governing their previous attempts (task demands, available resources, and their own skills) will also be present in the future.

The hypothetical scenarios tested in this study were created with reference to research on peak $\mathrm{VO}_{2}$. In those empirical studies, a linear increase in boys' peak $\mathrm{VO}_{2}$ was observed from 8 to 18 years of age. In girls, the trend was similar but less consistent than boys' values, which tended to plateau in the midteens (7). Peak $\mathrm{VO}_{2}$ was higher in boys than in girls, with the difference between them becoming significant after 12 years of age and gradually widening with increasing age $(8,9)$. In adulthood, peak $\mathrm{VO}_{2}$ started to decline with advancing age in both men and women (10-12). Although people who are overweight or obese did not have an impaired peak $\mathrm{VO}_{2}$ relative to fat-free mass, individuals with obesity had a reduced peak $\mathrm{VO}_{2}$ relative to body weight (13). Additionally, hyperthermia caused by exercising in a hot environment impaired peak $\mathrm{VO}_{2}$ (14-16). Moreover, peak $\mathrm{VO}_{2}$ decreased with the partial pressure of inspired oxygen at high altitudes (17). Although prolonged periods of aerobic training improved peak $\mathrm{VO}_{2}$ considerably, it decreased within weeks after training cessation (18). The reviewed literature provided the basis for our development of the inventory used in this study.

As shown in previous research, concept learning is limited by age-graded cognitive development. According to Piaget's model of cognitive development, one developmental milestone is the ability to understand hypothetical situations (19). Given the volume nature of peak $\mathrm{VO}_{2}$, the Piagetian idea of conservation is useful to conceptualize the level of understanding of peak $\mathrm{VO}_{2}$. Conservation, defined as the ability to mentally preserve the attribute of an object/an observation despite the change of appearance, is critical for performing mental computation on a wide range of dimensions such as volume, length, area, etc. Jean Piaget developed a cognitive development model with four successive stages: sensorimotor stage (roughly 0-2 years), preoperational stage (roughly 2-7 years), concrete operational stage (roughly 7-11 years) and the formal operational stage (11 years and beyond). Along these stages, children's thinking changes from concrete to abstract. They develop the ability to replace overt actions by mental representations, with egocentrism and centration diminishes. Children develop more eye for detail, their information processing capacities increase, and their problem solving becomes more and more advanced. Based on the previous studies of conservation and the model of cognitive development, we hypothesize that the understanding of peak $\mathrm{VO}_{2}$ differs in children of different ages. Hence, a cognitive development perspective was adopted to examine the understanding of peak $\mathrm{VO}_{2}$ in school children aged $8-16$ years. The results will provide insight into age-related differences in the interpretation of peak $\mathrm{VO}_{2}$.

Gender differences were noted in previous study. In general, girls were found to be less active and skillful in movement during physical exercise (PE) lesson. Owing to lower levels of perceived 
motor competence, girls did not enjoy as much as boys did in PE lessons (20). Such gender differences have prompted curricular designers to include arts-based teaching in PE lessons, such as dance (21). Apart from the environmental change, it is imperative to identify the cognition in girls that may hinder or facilitate their participation in a board range of physical activities. In this study, we examined if girls' and boys' understanding of peak $\mathrm{VO}_{2}$ was different.

Extended from previous studies that showed the link between peak $\mathrm{VO}_{2}$, its determinants and the resulting health conditions, this study examines the understanding of peak $\mathrm{VO}_{2}$ among children and adolescents. The major research question that motivates the current study is: "What is the understanding of peak $\mathrm{VO}_{2}$ in children aged 8-16 years old?" Using a cross-sectional design, we tested nine groups of participants ranging from 8 to 16 years old. This research design allows the examination of age-related differences, which is critical for identifying the optimal time and level of difficulty for introducing the concept of peak $\mathrm{VO}_{2}$. A more specific research question is: Does age affect the extent to which a student understands the concept of peak $\mathrm{VO}_{2}$ ? According to the stage theory of cognitive development (19), children over 6 (in the "pre-operational" stage) should be able to understand concepts involving conservation ability. These children are expected to be able to decide when peak $\mathrm{VO}_{2}$ remained unchanged, even something observable has been altered. Elder children, about 712 years old, will be able to apply inductive reasoning to solve an abstract question (in the "concrete operational" stage). Twelveyear-old or above have more advanced logical thinking. They can apply deductive reasoning to solve problems (in the "formal operational" stage). We answered this question by analyzing the accuracy and the choice of answers. Further to accuracy, we planned to infer the student participants' way of thinking when tackling the questions about peak $\mathrm{VO}_{2}$. We conducted error analyses to examine how the antecedent and the resulting peak $\mathrm{VO}_{2}$ were perceived by students of different ages. The next research question is: "Is there gender difference in the understanding of the concept of peak $\mathrm{VO}_{2}$ ?" We will compare the accuracy and the choice of answers between the male and female groups, with the consideration of age.

\section{MATERIALS AND METHODS}

Participants in this study were recruited from 12 primary and 19 secondary schools in Hong Kong through stratified sampling. These schools are mainstream schools that admitted students with normal IQ scores. Ethics approval was obtained from ethics committee of the Joint Chinese University of Hong Kong New Territory East Cluster Clinical Research Ethics Committee (CRE Ref. No. 2013.574). Before data collection, informed written consents were obtained from the student participants and their parents. On the day of testing, the experimenters informed the children the nature of the testing and their rights, such as voluntary participation. Participants were tested individually in a quiet meeting room by trained Psychology undergraduate students under the supervision of the authors of this paper. The whole testing session was normally last for 15 minutes.

The Peak $\mathrm{VO}_{2}$ Understanding Inventory was drafted, revised and confirmed by the authors. First, we brainstormed a range of possible and impossible conditions in which peak $\mathrm{VO}_{2}$ may increase, decrease or remain unchanged. The inventory items shared a standard format eliciting prefactual thinking [if (under a circumstance), then (resulting peak $\mathrm{VO}_{2}$ )]. After a careful selection, a total of 20 items were selected to be included in the inventory (Table 1). Each item presented the participants with a scenario, and they were asked to indicate whether peak $\mathrm{VO}_{2}$ would "remain unchanged," "increase," or "decrease," or that there was "insufficient information for a definite answer." The items described three main types of change: (a) environmental change (6 items), referring to a change in the external environment; (b) behavioral change (7 items), referring to a change in a person's actions; and (c) bodily change (6 items), referring to a change in internal physical condition. The remaining item was about general knowledge on peak $\mathrm{VO}_{2}$. Before the participants answering the twenty questions, they were introduced with the concept peak $\mathrm{VO}_{2}$ and its formal definition. Each correctly answered item was scored one point. The maximum score for this inventory was 20 points. The reliability of the scale, in terms of internal consistency and assessed by the Cronbach's alpha test, is moderate $[\alpha=0.60$ (22)].

\section{Statistical Analysis}

Data are presented as means, standard deviations or percentage. The one-way analysis of variance (ANOVA) with age group as the between-subject factor, followed by post hoc Tukey's HSD tests, was performed to compare the performance of the inventory across different age groups. Chi-squared tests were conducted to examine the association between age (8-16 years) and response ( $1=$ increase, $2=$ unchanged, $3=$ decrease, $4=$ uncertain). Upon a significant Pearson chi-squared value $(p<0.05)$ was detected, post hoc analyses were performed to identify which cell had significantly more or fewer count as expected. A standardized residual larger than 1.96 indicated a significant difference at $95 \%$ confidence interval. A positive value exceeding 1.96 indicated that the actual count was more than the expected count; whereas, a negative value $<-1.96$ indicated that the count was fewer than the expected count.

\section{RESULTS}

The final sample comprised 549 children and adolescents. The characteristics of each group are presented in Table 2. The descriptive statistics of the peak $\mathrm{VO}_{2}$ inventory among the nine age groups are presented in Table 3. A two-way analysis of variance (ANOVA) was computed to test the effect of age and gender using General Linear Model analysis in SPSS. There was a significant main effect of age on the peak $\mathrm{VO}_{2}$ inventory total scores, $F_{(8,531)}=3.91, p<0.05$, partial $\eta^{2}=79$. There was a nonsignificant main effect of gender on the peak $\mathrm{VO}_{2}$ inventory total scores, $F_{(1,531)}=0.09, p=0.76$. The age $\mathrm{x}$ gender interaction effect was not significant, $F_{(8,531)}=0.71, p=0.68$. A post hoc Tukey's HSD test further revealed that the youngest 
TABLE 1 | Items of the Peak $\mathrm{VO}_{2}$ Understanding Inventory and corresponding answers.

\begin{tabular}{|c|c|c|c|}
\hline Types of factors & Item no. & Items & Answers: Peak $\mathrm{VO}_{2}$ will become \\
\hline \multirow[t]{5}{*}{ Environmental } & 1 & When the oxygen level in the air increases, & Unchanged \\
\hline & 2 & When in the mountains where the air is thin, & Decrease \\
\hline & 3 & When inside an oxygenated compartment, & Unchanged \\
\hline & 4 & When the surrounding air is oxygen-depleted, & Decrease \\
\hline & 5 & When doing exercise in an extremely high temperature, & Decrease \\
\hline & 8 & After short, vigorous exertion such as chasing a bus, & Unchanged \\
\hline & 9 & When a person plays an exciting game in an amusement park, & Unchanged \\
\hline & 10 & When a person wants to intentionally increase peak $\mathrm{VO}_{2}$, & Unchanged \\
\hline & 11 & When a person falls into deep sleep at night, & Unchanged \\
\hline & 12 & When a person does exercise regularly but then stops for a few months, & Decrease \\
\hline \multirow{4}{*}{ Bodily } & 16 & When a person's cardiovascular function improves, & Increase \\
\hline & 17 & When a person's physical condition becomes worse because of illness, & Decrease \\
\hline & 18 & When a person grows from adolescence to adulthood, & Increase \\
\hline & 19 & When a person grows from adulthood to old age, & Decrease \\
\hline General knowledge & 20 & In general, the peak $\mathrm{VO}_{2}$ in boys is (higher/lower) than in girls. & Higher \\
\hline
\end{tabular}

TABLE 2 | Number of children in each age group (ranging from 8 to 16 years old).

\begin{tabular}{lcccc}
\hline Age group & Age (month) (mean, S.D.) & N (count) & N (\%) & Gender ratio (male: female) \\
\hline 8 & $103.69(3.46)$ & 59 & 10.7 & 1.1 .1 \\
9 & $112.95(3.56)$ & 70 & 12.8 & $1: 1$ \\
10 & $125.69(3.61)$ & 63 & 11.5 & $1: 0.9$ \\
11 & $137.81(3.25)$ & 40.9 & $1: 1.85$ \\
12 & $150.93(2.96)$ & 73 & 8.4 & $1: 1$ \\
13 & $161.67(3.80)$ & 51 & 9.3 & $1: 0.97$ \\
14 & $173.37(3.57)$ & 70 & 13.8 & $1: 1.12$ \\
15 & $185.87(3.21)$ & 57 & 10.4 & $1: 0.94$ \\
16 & $197.01(3.88)$ & 549 & 100.0 & $1: 0.9$ \\
Total & $149.43(31.07)$ & & $1: 1.05$
\end{tabular}

age group (i.e., 8-year-old group) performed significantly worse than did the 11-year-old $(p<0.05), 14$-year-old $(p<0.05)$, and 15 -year-old $(p<0.01)$ groups.

The percentage of correct count for each item across the nine age groups is presented in Table 4. Results of chi-square tests on items of environmental change, behavioral change, and bodily change are presented as follows:

\section{Environmental Factors}

Concerning the item "What will be the peak $\mathrm{VO}_{2}$, when the oxygen level in the air increases" [Q1, unchanged; $\chi_{(24)}^{2}=43.49$, $p<0.01$ (0.009)], post hoc comparison indicated that significantly more participants in the 8-year-old group chose the option "uncertain" (standardized residual $=2.7$ ), whereas the 16-yearold group chose the correct answer "unchanged" significantly more often (standardized residual $=2.9$ ).
Regarding the item "What will be the peak $\mathrm{VO}_{2}$, when in the mountains where the air is thin" [Q2, decrease; $\chi_{(24)}^{2}=39.93, p$ $<0.05(0.02)$ ], post hoc comparison indicated that significantly more participants in the 9-year-old group chose the option "uncertain" ( standardized residual $=2.8$ ), whereas significantly more participants in the 16-year-old group chose the correct answer "decrease" (standardized residual $=2.5$ ).

For the item "What will be the peak $\mathrm{VO}_{2}$, when inside an oxygenated compartment" [Q3, unchanged; $\chi_{(24)}^{2}=$ 31.61, $p=0.13$ ], participants in all age groups had similar response frequencies.

Concerning the item "What will be the peak $\mathrm{VO}_{2}$, when the surrounding air is oxygen-depleted" [Q4, decrease; $\chi_{(24)}^{2}=55.54$, $p<0.001(0.000)]$, significantly more participants in the 16year-old group gave the correct answer "decrease" (standardized residual $=3.9$ ). 
TABLE 3 | Descriptive statistics of total scores for the Peak $\mathrm{VO}_{2}$ Understanding Inventory.

\begin{tabular}{lcccc}
\hline Age group & $\begin{array}{c}\text { Mean (S.D.) } \\
\text { in both males and females }\end{array}$ & $\begin{array}{c}\text { Mean (S.D.) } \\
\text { in males }\end{array}$ & $\begin{array}{c}\text { Mean (S.D.) } \\
\text { in females }\end{array}$ & $t$-statistics $\boldsymbol{t}$ (df); $\boldsymbol{p}$-value \\
\hline 8 & $7.41(2.62)$ & $7.68(2.81)$ & $7.16(2.46)$ & $t(57)=0.75 ; p=0.45$ \\
9 & $8.00(2.84)$ & $8.43(2.80)$ & $7.57(2.87)$ & $t(68)=1.26 ; p=0.21$ \\
10 & $8.32(2.00)$ & $8.42(1.93)$ & $8.20(2.10)$ & $t(61)=0.44 ; p=0.66$ \\
11 & $9.10(2.29)$ & $8.71(2.79)$ & $9.31(1.98)$ & $t(58)=-0.95 ; p=0.34$ \\
12 & $8.11(2.64)$ & $7.57(2.35)$ & $8.65(2.85)$ & $t(44)=-1.41 ; p=0.16$ \\
13 & $8.59(2.43)$ & $8.59(2.91)$ & $8.58(1.85)$ & $t(71)=0.02 ; p=0.98$ \\
14 & $8.96(2.53)$ & $9.08(3.02)$ & $8.85(2.07)$ & $t(49)=0.32 ; p=0.74$ \\
15 & $9.07(2.64)$ & $9.25(2.59)$ & $8.88(2.72)$ & $t(68)=0.57 ; p=0.56$ \\
16 & $8.74(2.87)$ & $8.73(2.65)$ & $8.74(3.15)$ & $t(55)=-0.01 ; p=0.99$ \\
Total & $8.48(2.59)$ & $8.52(2.67)$ & $8.44(2.51)$ & $t(547)=0.36 ; p=0.71$ \\
\hline
\end{tabular}

TABLE 4 | Percentage correct of individual item in the Peak $\mathrm{VO}_{2}$ Understanding Inventory among children between 8-16 years old.

\begin{tabular}{|c|c|c|c|c|c|c|c|c|c|c|}
\hline Question/age & 8 yo & 9 yo & 10 yo & 11 yo & 12 yo & 13 yo & 14 yo & 15 yo & 16 yo & Total \\
\hline Q1 & 15.3 & 22.9 & 28.6 & 21.7 & 21.7 & 24.7 & 41.2 & 34.3 & 49.1 & 28.6 \\
\hline Q2 & 44.1 & 52.9 & 55.6 & 68.3 & 58.7 & 60.3 & 60.8 & 57.1 & 38.6 & 55.2 \\
\hline Q3 & 13.6 & 27.1 & 33.3 & 33.3 & 32.6 & 38.4 & 35.3 & 40.0 & 45.6 & 33.3 \\
\hline Q4 & 66.1 & 68.6 & 74.6 & 73.3 & 71.7 & 61.6 & 54.9 & 57.1 & 49.1 & 64.1 \\
\hline Q5 & 16.9 & 18.6 & 14.3 & 15.0 & 13.0 & 15.1 & 21.6 & 11.4 & 8.8 & 14.9 \\
\hline Q6 & 15.3 & 5.7 & 11.1 & 13.3 & 13.0 & 11.0 & 3.9 & 7.1 & 7.0 & 9.7 \\
\hline Q7 & 33.9 & 34.3 & 28.6 & 30.0 & 23.9 & 17.8 & 19.6 & 30.0 & 28.1 & 27.5 \\
\hline Q8 & 27.1 & 42.9 & 33.3 & 35.0 & 37.0 & 42.5 & 21.6 & 38.6 & 42.1 & 36.1 \\
\hline Q9 & 16.9 & 27.1 & 25.4 & 16.7 & 15.2 & 16.4 & 19.6 & 20.0 & 24.6 & 20.4 \\
\hline Q10 & 27.1 & 22.9 & 30.2 & 31.7 & 34.8 & 54.8 & 52.9 & 40.0 & 38.6 & 37.0 \\
\hline Q11 & 30.5 & 31.4 & 34.9 & 41.7 & 19.6 & 35.6 & 25.5 & 35.7 & 40.4 & 33.3 \\
\hline Q12 & 49.2 & 57.1 & 60.3 & 56.7 & 52.2 & 60.3 & 66.7 & 58.6 & 63.2 & 58.3 \\
\hline Q13 & 37.3 & 42.9 & 30.2 & 51.7 & 39.1 & 41.1 & 37.3 & 38.6 & 40.4 & 39.9 \\
\hline Q14 & 32.2 & 10.0 & 30.2 & 25.0 & 30.4 & 23.3 & 31.4 & 18.6 & 19.3 & 23.9 \\
\hline Q15 & 67.8 & 77.1 & 81.0 & 85.0 & 69.6 & 80.8 & 84.3 & 80.0 & 86.0 & 79.2 \\
\hline Q16 & 54.2 & 52.9 & 58.7 & 70.0 & 60.9 & 67.1 & 64.7 & 68.6 & 61.4 & 62.1 \\
\hline Q17 & 45.8 & 57.1 & 54.0 & 63.3 & 63.0 & 54.8 & 64.7 & 71.4 & 61.4 & 59.4 \\
\hline Q18 & 54.2 & 57.1 & 61.9 & 78.3 & 67.4 & 68.5 & 84.3 & 80.0 & 68.4 & 68.7 \\
\hline Q19 & 32.2 & 21.4 & 20.6 & 35.0 & 26.1 & 31.5 & 35.3 & 48.6 & 26.3 & 31.0 \\
\hline Q20 & 32.2 & 21.4 & 20.6 & 35.0 & 26.1 & 31.5 & 35.3 & 48.6 & 26.3 & 31.0 \\
\hline
\end{tabular}

Regarding the item "What will be the peak $\mathrm{VO}_{2}$, when doing exercise in an extremely high temperature" (Q5, decrease), no significant difference in the frequency of answers across the eight age groups was observed $\left[\chi_{(24)}^{2}=29.45, p=0.20\right]$.

For the item "What will be the peak $\mathrm{VO}_{2}$, when the peak $\mathrm{VO}_{2}$ analyzer malfunctions" [Q6, uncertain; $\left.\chi_{(24)}^{2}=57.27, p<0.001\right]$, significantly more 9- and 10 -year-old participants chose the option "increase" (standardized residual $=2.5$ and 2.3, respectively), and significantly more 16-year-old participants chose "unchanged" (standardized residual = 2.0). Compared with other age groups, the 15-year-old group chose the option "uncertain" significantly more often (standardized residual $=2.5$ ).

\section{Behavioral Factors}

The participants were then asked, "What will be the peak $\mathrm{VO}_{2}$, when a person does high-intensity aerobic exercise on a regular basis?" (Q7, increase). Significantly more 9-year-old participants chose the option "uncertain" $\left[\chi_{(24)}^{2}=51.22, p<\right.$ 0.01 , standardized residual $=4.7$.

Next, the participants were asked, "What will be the peak $\mathrm{VO}_{2}$, after short, vigorous exertion such as chasing a bus?" (Q8, unchanged). No significant difference across all age groups was observed $\left[\chi_{(24)}^{2}=36.01, p=0.05\right]$. Similar results were obtained for other scenarios in this category: "What will be the peak $\mathrm{VO}_{2}$, when a person plays an exciting game in an amusement park" [Q9, unchanged; $\left.\chi_{(24)}^{2}=27.70, p=0.59\right]$; "What will be the peak $\mathrm{VO}_{2}$, when a person wants to intentionally increase peak $\mathrm{VO}_{2}$ ” 
[Q10, unchanged; $\left.\chi_{(24)}^{2}=28.41, p=0.24\right]$; "What will be the peak $\mathrm{VO}_{2}$, when a person falls into deep sleep at night" [Q11, unchanged; $\left.\chi_{(24)}^{2}=35.14, p=0.06\right]$; and "What will be the peak $\mathrm{VO}_{2}$, when a person does exercise regularly but then stops for a few months" [Q12, decrease; $\chi_{(24)}^{2}=28.24, p=0.25$ ].

However, for the item "What will be the peak $\mathrm{VO}_{2}$, after taking a pro-cardiovascular health supplement" (Q13, uncertain) a significant group difference was found $\left[\chi_{(24)}^{2}=57.99, p<\right.$ $0.001]$. Post hoc comparison revealed that significantly more 16 -year-olds chose "unchanged" (standardized residual $=2.1$ ), significantly more 8-year-olds chose "decrease" (standardized residual $=2.6$ ), and significantly more 13-year-olds chose "uncertain" (standardized residual = 2.5).

\section{Bodily Factors}

For the item "What will be the peak $\mathrm{VO}_{2}$, when a person gains weight and becomes obese" (Q14, decrease), the pattern of responses across all groups was not significant $\left[\chi_{(24)}^{2}=29.82\right.$, $p=0.19$.

For the item "What will be the peak $\mathrm{VO}_{2}$, when a person loses weight" (Q15, uncertain), a significant group difference was observed $\left[\chi_{(24)}^{2}=46.47, p<0.01\right]$. Post hoc analysis indicated that significantly more participants chose "increase" in the 9year-old group (standardized residual $=2.4$ ) and "unchanged" in the 15-year-old group (standardized residual $=2.6$ ).

Regarding the item "What will be the peak $\mathrm{VO}_{2}$, when a person's cardiovascular function improves" (Q16, increase), no significant difference was observed $\left[\chi_{(24)}^{2}=28.27, p=0.24\right]$.

A significant overall group difference was found for the item "What will be the peak $\mathrm{VO}_{2}$, when a person's physical condition deteriorates because of illness" [Q17, decrease; $\chi_{(24)}^{2}=$ $36.40, p<0.05]$. However, post hoc analysis revealed no specific group difference.

No significant group difference was observed for the remaining two items: "What will be the peak $\mathrm{VO}_{2}$, when a person grows from adolescence to adulthood" [Q18, increase; $\chi_{(24)}^{2}=$ $29.14, p=0.21$ ] and "What will be the peak $\mathrm{VO}_{2}$, when a person grows from adulthood to old age" [Q19, decrease; $\chi_{(24)}^{2}=34.26$, $p=0.08]$.

Regarding the item about gender difference, "the peak $\mathrm{VO}_{2}$ in boys is (higher/lower) than in girls" [Q20, higher; $\chi_{(24)}^{2}=26.57$, $p=0.32$ ], no group difference was found.

\section{Error Analysis by Gender Group}

To identify if there was recurring patterns of errors specific to gender, the same non-parametric "age (8-16 years old) $\mathrm{x}$ answer options (increase, decrease, unchanged, uncertain)" chi-square test was conducted on the two gender groups independently.

In female students, seven significant differences were observed (chi-square $<0.05$ or below). When asked about the resulting peak $\mathrm{VO}_{2}$, the ten-year-old females were more inclined to think that the peak $\mathrm{VO}_{2}$ remained unchanged (standardized residual $=2.0$ ) while the 13-year-old females were more inclined to think that the peak $\mathrm{VO}_{2}$ was uncertain. The results further showed that, the 8-year-old and 10-year-old females were inclined to choose the answer option "uncertain" for the three questions they answered incorrectly ( standardized residuals $=2.0-3.5$ ).

In male students, when they were asked about the resulting peak $\mathrm{VO}_{2}$ in an extremely hot environment, the 12- and 14year old students were more inclined to respond "uncertain" (standardized residuals $=2.1$ and 2.3 , respectively) while the 9-year-old students were more likely to suggest an increase (standardized residuals $=2.4$ ). The 8 -year-old males were more inclined to think that peak $\mathrm{VO}_{2}$ would increase after taking some pro-cardiovascular health supplement (standardized residuals $=$ 2.1). The 16-year-old males are inclined to suggest that peak $\mathrm{VO}_{2}$ remains unchanged when a person loses weight (standardized residuals $=2.8$ ). When asked about the resulting peak $\mathrm{VO}_{2}$ after a person has just completed some vigorous exercise, 9-, 12-, and 15year-old males were inclined to suggest "increase," "decrease" and "uncertain," respectively (standardized residuals $=2.2,2.1,2.0$, respectively). The 9-year-old males responded relatively more "uncertain" when asked if a person stays on a mountain for some time (standardized residual $=4.2$ ). Interestingly, when asked what would happen if a person staying inside an oxygenated compartment, the 9-year-old males reported relatively more "decrease" (standardized residual $=2.0$ ) and somewhat less "increase" (standardized residual $=-2.1$ ), implying polarized opinion in this age group.

\section{DISCUSSION}

The primary aim of this cross-sectional study was to examine the understanding of the concept of peak $\mathrm{VO}_{2}$ in students aged 816 years. Our first research question asks if age is a significant factor that influences the level of understanding of peak $\mathrm{VO}_{2}$. As revealed by the total scores of the peak $\mathrm{VO}_{2}$ inventory, except for the youngest group of children (aged 8) who performed worse than the three older groups, no significant age effect was observed. Older participants did not always perform better than younger ones, a finding that did not conform to our expectation of an increasingly higher correct response rate with increasing age. This finding also suggests that the concept formation behind the understanding of peak $\mathrm{VO}_{2}$ cannot simply be explained by age-related cognitive development. Rather, peak $\mathrm{VO}_{2}$ is a concept that demands a multitude of reasoning skills to derive the factors affecting its volume, with a distinctive developmental pathway for each of these skills.

The participants' incorrect responses may be explained by their failure to form a possible causal link between antecedent (cause) and outcome (effect) for hypothetical situations. As mentioned, one critical skill for a proper understanding of peak $\mathrm{VO}_{2}$ may be prefactual thinking, a type of logical thought. Introducing the concept of peak $\mathrm{VO}_{2}$ through visualization, video simulation, multimedia learning materials, or real object models would be useful for students whose abstract reasoning skills are yet to fully developed. Given their underdeveloped knowledge of peak $\mathrm{VO}_{2}$, children and adolescents cannot be aware of its importance; even when this is explained to them, they cannot decide on what action may enhance peak $\mathrm{VO}_{2}$. Instead of general training in logical thinking, specific health-concept 
coaching is recommended in health education. One study demonstrated that people with a low aerobic capacity may have difficulty in sustaining more demanding activities (23), and another found that aerobic capacity contributed to cardiac workload and was associated with heart growth during childhood and adolescence (24).

Apart from age difference, we observed gender differences in choosing the answer out of four options, i.e., increase, decrease, unchanged, and uncertain. Female students were more inclined than male students to choose the answer option "uncertain" for the questions they responded incorrectly. Although we specified in the instruction that the answer option "uncertain" meant "the resulting peak $\mathrm{VO}_{2}$ is not certain," the respondents might choose this answer option when they were indecisive about their decision. In future research, we suggest using another word (e.g., "insufficient information to determine") to replace the word "uncertain."

As our results demonstrate, students aged 8-16 years have not yet developed a satisfactory level of understanding of the concept of peak $\mathrm{VO}_{2}$. Given the importance of moderate-to-vigorous physical activity (MVPA), it is necessary to promote health literacy earlier than 8 years old. Therefore, further studies need to be done on younger children and examine their understanding of peak $\mathrm{VO}_{2}$. The inventory provided in this study would be useful for educators and psychologists to further develop ageappropriate assessment tool for testing younger children. Our study has also highlighted the importance of direct measure of students' understanding of health literacy-related concepts. As our study shows that age is not a strong predictor of the knowledge of peak $\mathrm{VO}_{2}$, we suggest educators not to assume children in the same class or grade have a similar level of understanding of peak $\mathrm{VO}_{2}$. Instead, we suggest to create a physical literacy profile for each student and keep a record of his/her current and improved understanding of all the essential concepts about physical literacy. In particular, we encourage the sport practitioners to demonstrate to children and adolescents the link between physical fitness and the volume of peak $\mathrm{VO}_{2}$. Given the abstractness of the concept, we suggest to test students using standard method (e.g. a progressive treadmill test) so that the experience of running and obtaining the result of peak $\mathrm{VO}_{2}$ can promote students' understanding of the concept. To further use the knowledge of peak $\mathrm{VO}_{2}$ to promote the awareness of maintaining an optimal level of peak $\mathrm{VO}_{2}$, regular measure and review of peak $\mathrm{VO}_{2}$ is recommended. Apart from running, sport practitioners are advised to refer to the Ecological Dynamics framework to design age-appropriate physical activities and environments that can support the improvement of peak $\mathrm{VO}_{2}$ (25). For instance, redesigning the playground in a school to encourage more moderate-to-vigorous physical activities during school time. As indicated in our findings, many children and adolescents mistakenly believed that many conditions can increase the peak $\mathrm{VO}_{2}$. Thus, it is necessary to clarify with these people the exact conditions in which peak $\mathrm{VO}_{2}$ increases and results an improvement of physical fitness. For the planning of health literacy curriculum, our findings of gender differences suggest the need to include suitable examples of physical activities that can arouse the interest in male and female students. Apart from school settings, it is also essential to promote the awareness and importance of the concept of peak $\mathrm{VO}_{2}$ in a wider community. As noted in previous studies (26), parent's physical literacy have strong influences on their children, especially the negative ones. For example, parents who have poor knowledge of physical literacy do not know how to overcome the barriers (e.g., lack of time and information) that hinder their participation in physical activities. When their children face a similar situation, these parents do not know how to overcome such challenges for their children. Therefore, we believe home-school cooperation is needed in order to promote regular participation of physical activities. While we assume that knowing will induce behaviors, future studies on the contribution of the understanding of peak $\mathrm{VO}_{2}$ to the actual participation of physical activity is warranted.

To conclude, children and adolescents ranging from 8 to 16 years old have suboptimal understanding of the antecedent of peak $\mathrm{VO}_{2}$. Given that age and gender have an effect (though not as consistent as we predicted) on the understanding of peak $\mathrm{VO}_{2}$, it is necessary to take chronological age and gender into account when assessing the mastery of this knowledge. It is critical to develop effective method for educating children and adolescents the concept of peak $\mathrm{VO}_{2}$ and the implications of poor peak $\mathrm{VO}_{2}$.

\section{DATA AVAILABILITY STATEMENT}

The datasets that support the findings of this study are available on request from the corresponding author. The datasets are not publicly available due to privacy or ethical restrictions.

\section{ETHICS STATEMENT}

The studies involving human participants were reviewed and approved by Ethics committee of the Joint Chinese University of Hong Kong - New Territory East Cluster Clinical Research Ethics Committee. Informed and written consents were obtained from the student participants and their parents.

\section{AUTHOR CONTRIBUTIONS}

SW drafted the manuscript, performed the statistical analyses, and reviewed and revised the manuscript. CY coordinated and supervised data collection and entry and reviewed and revised the manuscript. AL obtained the funding for this project, supervised the data collection, and critically reviewed the manuscript. All the authors contributed to the article and approved the submitted version.

\section{FUNDING}

The project was supported by the Health and Medical Research Fund (Ref no. 02130486) of the Food and Health Bureau, and the General Research Fund (Ref no. 18608018) of the Research Grants Council, Hong Kong SAR Government, People's Republic of China.

\section{ACKNOWLEDGMENTS}

We thank all the schools and students participating in this project. 


\section{REFERENCES}

1. Carnethon MR, Gulati M, Greenland P. Prevalence and cardiovascular disease correlates of low cardiorespiratory fitness in adolescents and adults. JAMA. (2005) 294:2981-8. doi: 10.1001/jama.294.23.2981

2. Ortega FB, Ruiz JR, Castillo MJ, Sjostrom M. Physical fitness in childhood and adolescence: a powerful marker of health. Int J Obes. (2008) 32:111. doi: $10.1038 /$ sj.ijo.0803774

3. Whitehead ME, Durden-Myers EJ, Pot N. The Value of Fostering Physical Literacy. (2018) 37:252. doi: 10.1123/jtpe.2018-0139

4. Tremblay MS, Costas-Bradstreet C, Barnes JD, Bartlett B, Dampier D, Lalonde C, et al. Canada's physical literacy consensus statement: process and outcome. BMC Public Health. (2018) 18 (Suppl. 2):1034. doi: 10.1186/s12889-018-5903-x

5. Li MH, Sum RKW, Sit CHP, Wong SHS, Ha ASC. Associations between perceived and actual physical literacy level in Chinese primary school children. BMC Public Health. (2020) 20:207. doi: 10.1186/s12889-020-8318-4

6. Society AT. ATS/ACCP statement on cardiopulmonary exercise testing. Am J Respir Crit Care Med. (2003) 167:211-77. doi: 10.1164/rccm.167.2.211

7. Bergeron MF, Mountjoy M, Armstrong N, Chia M, Cote J, Emery CA, et al. International Olympic Committee consensus statement on youth athletic development. Br J Sports Med. (2015) 49:843-51. doi: 10.1136/bjsports-2015-094962

8. Armstrong N, Williams J, Balding J, Gentle P, Kirby B. The peak oxygen uptake of British children with reference to age, sex and sexual maturity. Eur J Appl Physiol Occup Physiol. (1991) 62:369-75. doi: 10.1007/BF00634975

9. Rowland TW. The Development of Aerobic Fitness in Children. London: E \& FN Spon (1997). p. 179-90.

10. Astrand I. Aerobic work capacity in men and women with special reference to age. Acta Physiol Scand Suppl. (1960) 49:1-92.

11. Pimentel AE, Gentile CL, Tanaka H, Seals DR, Gates PE. Greater rate of decline in maximal aerobic capacity with age in endurance-trained than in sedentary men. J Appl Physiol. (2003) 94:2406-13. doi: 10.1152/japplphysiol.00774.2002

12. Tanaka H, Desouza CA, Jones PP, Stevenson ET, Davy KP, Seals DR. Greater rate of decline in maximal aerobic capacity with age in physically active vs. sedentary healthy women. J Appl Physiol. (1997) 83:194753. doi: 10.1152/jappl.1997.83.6.1947

13. Goran M, Fields DA, Hunter GR, Herd SL, Weinsier RL. Total body fat does not influence maximal aerobic capacity. Int J Obes Relat Metab Disord. (2000) 24:841-8. doi: 10.1038/sj.ijo.0801241

14. Arngrimsson SA, Petitt DS, Borrani F, Skinner KA, Cureton KJ. Hyperthermia and maximal oxygen uptake in men and women. Eur J Appl Physiol. (2004) 92:524-32. doi: 10.1007/s00421-004-1053-1

15. Gonzalez-Alonso J, Calbet JA. Reductions in systemic and skeletal muscle blood flow and oxygen delivery limit maximal aerobic capacity in humans. Circulation. (2003) 107:824-30. doi: 10.1161/01.CIR.0000049746. $29175.3 \mathrm{~F}$
16. Pirnay F, Deroanne R, Petit JM. Maximal oxygen consumption in a hot environment. J Appl Physiol. (1970) 28:6425. doi: 10.1152/jappl.1970.28.5.642

17. Wehrlin JP, Hallen J. Linear decrease in .VO2max and performance with increasing altitude in endurance athletes. Eur J Appl Physiol. (2006) 96:40412. doi: 10.1007/s00421-005-0081-9

18. Neufer PD. The effect of detraining and reduced training on the physiological adaptations to aerobic exercise training. Sports Med. (1989) 8:302-20. doi: 10.2165/00007256-198908050-00004

19. Piaget J. Construction of Reality in the Child. London: Routledge \& Kegan Paul (1957)

20. Cairney J, Kwan MYW, Velduizen S, Hay J, Bray SR, Faught BE. Gender, perceived competence and the enjoyment of physical education in children: a longitudinal examination. Int J Behav Nutr Phys Act. (2012) 9:26. doi: 10.1186/1479-5868-9-26

21. Shen B, Chen A, Tolley H, Scrabis KA. Gender and interest-based motivation in learning dance. J Teach Phys Educ. (2003) 22:396409. doi: 10.1123/jtpe.22.4.396

22. Robinson JP, Shaver PR, Wrightsman LS. Criteria for scale selection and evaluation. In Robinson JP, Shaver PR, Wrightsman LS, editors. Measures of Personality Social Psychological Attitude. San Diego, CA: Academic Press, Inc. (1991) p. 1-15.

23. Talbot LA, Metter EJ, Fleg JL. Leisure-time physical activities and their relationship to cardiorespiratory fitness in healthy men and women 18-95 years old. Med Sci Sports Exerc. (2000) 32:417-25. doi: 10.1097/00005768-200002000 00024

24. Janz KF, Dawson JD, Mahoney LT. Predicting heart growth during puberty: the Muscatine study. Pediatrics. (2000) 105:E63. doi: 10.1542/peds.105. $5 . e 63$

25. O'Sullivan M, Davids K, Woods CT, Rothwell M, Rudd J. Conceptualizing physical literacy within an ecological dynamics framework. Quest. (2020) 72:448-62. doi: 10.1080/00336297.2020.1799828

26. Ha AS, Chan W, Ng JYY. Relation between perceived barrier profiles, physical literacy, motivation and physical activity behaviors among parents with a young child. Int J Environ Res Public Health. (2020) 17:4459. doi: 10.3390/ijerph17124459

Conflict of Interest: The authors declare that the research was conducted in the absence of any commercial or financial relationships that could be construed as a potential conflict of interest.

Copyright (c) 2021 Wong, Yu and Li. This is an open-access article distributed under the terms of the Creative Commons Attribution License (CC BY). The use, distribution or reproduction in other forums is permitted, provided the original author(s) and the copyright owner(s) are credited and that the original publication in this journal is cited, in accordance with accepted academic practice. No use, distribution or reproduction is permitted which does not comply with these terms. 